\title{
Influence of neoadjuvant chemotherapy on prognosis of patients with synovial sarcoma
}

\author{
Yanan Wu, Wenzhi Bi , Gang Han, Jinpeng Jia and Meng Xu
}

\begin{abstract}
Background: This study aimed to explore the clinical efficacy of neoadjuvant chemotherapy combined with surgery in primary synovial sarcoma of the limbs and trunk through retrospective analysis of patients with primary synovial sarcoma of the limbs and trunk treated by this treatment in our hospital.

Methods: A total of 89 patients diagnosed with synovial sarcoma were enrolled in this study between January 2005 and December 2011 in PLA General Hospital. Most of the patients received neoadjuvant chemotherapy combined with operative treatment (84.3\%), 10.1\% of them received adjuvant chemotherapy combined with operative treatment, and only $5.6 \%$ received merely operative treatment. The influence on the prognosis of patients with synovial sarcoma was analyzed by the statistics overall survival (OS), progression-free survival (PFS), local control (LC), and freedom from distant metastasis (FFDM).

Results: The median follow-up time was 68.6 months. The 5-year OS, 5-year PFS, 5-year LC, and 5-year FFDM of the patients were $80.2,60.5,78.8$, and $80.8 \%$, respectively. The OS of the patients with a tumor size $>5 \mathrm{~cm}$ was lower (91.4 vs $73.1 \%, P<0.05)$. Besides, the OS and FFDM of neoadjuvant chemotherapy were better than those of adjuvant chemotherapy ( 84.5 vs $55.6 \%, P=0.015$, and 83.8 vs $55.6 \%, P=0.028$, respectively). However, there was no significant difference in the LC and PFS.

Conclusions: Neoadjuvant chemotherapy was beneficial for patients with synovial sarcoma, and it could improve survival time and control distant metastasis. Tumor size was an important factor influencing patients' prognosis.
\end{abstract}

Keywords: Synovial sarcoma, Neoadjuvant chemotherapy, Overall survival, Freedom from distant metastasis

\section{Background}

Synovial sarcoma is a high-grade soft tissue sarcoma with poor prognosis and accounts for $5 \sim 10 \%$ of soft tissue sarcomas [1]. It commonly occurs in young people; the age of onset is usually 15 to 40 years old. Synovial sarcoma is not tumor derived from synovial tissues, but it was named as such because it is frequently seen in soft tissues around the joints, which were mistaken to be derived from synovial tissues. However, it has been proved that synovial sarcoma could occur in multiple sites and organs. The origin of synovial sarcoma is not very clear, and nervous tissue, muscular tissue, and mesenchymal stem cells are likely to be its source [2]. Pathologically, synovial sarcoma is divided into unipolar type, bipolar type, and undifferentiated type. It possesses a constant chromosome translocation, commonly

\footnotetext{
* Correspondence: biwenzhi@sina.com

Department of Bone Tumor, The General Hospital of the People's Liberation Army, Beijing 100853, China
}

(c) The Author(s). 2017 Open Access This article is distributed under the terms of the Creative Commons Attribution 4.0 International License (http://creativecommons.org/licenses/by/4.0/), which permits unrestricted use, distribution, and reproduction in any medium, provided you give appropriate credit to the original author(s) and the source, provide a link to the Creative Commons license, and indicate if changes were made. The Creative Commons Public Domain Dedication waiver (http://creativecommons.org/publicdomain/zero/1.0/) applies to the data made available in this article, unless otherwise stated. translocation includes gene fusion between the SYT gene in chromosome 18 and the SSX1 or SSX2 gene in chromosome X and occasionally gene fusion with SSX4 [3]. Synovial sarcoma can occur in all parts of the body, but $80 \%$ of it is in the extremities [4]. It also easily metastasizes to organs, $70 \%$ to the lung and $10 \sim 20 \%$ to the bone. Whether synovial sarcoma has a propensity to metastasize to regional lymph nodes still remains a matter of debate [5, 6]. Weingrad and Rosenberg reported that lymphatic metastasis accounted for $17 \%$ of synovial sarcoma metastases [7].

In a previous study, it has been reported that the influencing factors for the prognosis of patients with synovial sarcoma included age, tumor size, tumor site, tumor staging, tumor pathological pattern, treatment, and surgical resection margin, which are still controversial. In order to further analyze and obtain the influencing risk factors for the 
prognosis of the disease, 89 patients with synovial sarcoma were enrolled in this 9-year single-center study. According to whether they were receiving neoadjuvant chemotherapy, the patients were divided into two groups. Through a comparative analysis of patient situation and prognosis in the two groups, the influence of neoadjuvant chemotherapy on the patients' prognosis was demonstrated.

\section{Methods}

\section{Patients}

A total of 89 patients diagnosed with synovial sarcoma were enrolled in this study between January 2005 and December 2011 in PLA General Hospital, and the last follow-up time was December 2014. The inclusion criterion is confirmed pathological diagnosis by an authorized pathologist in our hospital through tumor histological characteristics of the biopsy specimen and immunohistochemistry. The exclusion criteria are as follows: (1) patients diagnosed with synovial sarcoma but with distant metastases, (2) patients with other tumor history during or before the diagnosis of synovial sarcoma, (3) patients who received radiotherapy after being diagnosed with synovial sarcoma.

Tumor staging was done based on the patients' medical history, physical examination, chest CT examination, $\mathrm{X}$-ray, and MRI of local primary tumors. The relevant medical records were identified by the Ethics Committee of PLA General Hospital, and all the patients had signed the informed consent form.

\section{Treatment}

The main treatment for soft tissue tumor was neoadjuvant chemotherapy and extended resection of local tumor. When the tumor had invaded important nerves and blood vessels, and extended resection could not guarantee the patient's safety after resection, amputation was done. The patients receiving neoadjuvant chemotherapy received chemotherapy for approximately one to three treatment courses before surgery, approximately one to six treatment courses after surgery, and one repeat course every $3 \sim 4$ weeks. The specific condition of the chemotherapy course was made according to the tolerance degree of the patients on chemotherapy drugs, response after tumor chemotherapy, and family economic status. MAID (mesna, adriamycin, ifosfamide, and dacarbazine) protocols were used to treat the patients. The dose, administration method, and administration time of the chemotherapy drugs were based on the protocol shown in Table 1. As for the patients receiving neoadjuvant chemotherapy, after the last chemotherapy before surgery, we performed a routine MRI test on the tumor site and made a surgery plan according to the MRI features. Moreover, we still used MAID protocols to the patients with adjuvant chemotherapy for approximately one to six treatment courses after surgery.

\section{Assessment criteria for the results}

Based on the survival state and clinical manifestation in the final follow-up, overall survival (OS), progression-free survival (PFS), local control (LC), and freedom from distant metastasis (FFDM) were analyzed. The starting time of treatment was defined as the chemotherapy or surgery time for the first time in our hospital. The starting and the ending time of related indexes were from the treatment to the occurrence of related events or the final follow-up. The ending related events for related indexes were as follows: for OS, death caused by any reason; for PFS, occurrence of relapse or metastasis; for LC, occurrence of local recurrence; for FFDM, occurrence of distant metastasis.

\section{Statistical analysis}

The data was analyzed by SPSS 19.0 (IBM, Chicago, USA). Measurement data with normal distribution were presented as mean $\pm \mathrm{SD}$, and counted data were presented as percentage (\%). Comparisons between groups of measurement data with normal distribution were analyzed by the $t$ test, and counted data were analyzed by the $\chi^{2}$ test. Survival analysis was done by the Kaplan-Meier survival curve and log-rank test. Univariate and multivariate analyses were conducted by the Cox regression model. All the statistical tests were bilateral.

\section{Results}

\section{Baseline information of patients}

There were 46 males and 43 females with an average age of 32.5 years (aged 10 70) in this study. Besides, 30 patients were less than 25 years old at the time of initial diagnosis. The average tumor size was $6.5 \mathrm{~cm}(3 \sim 17 \mathrm{~cm})$. Thirty-five patients had tumor sizes smaller than $5 \mathrm{~cm}$. The distributions of the tumor site were as follows: lower limb 52 cases (58.4\%), upper limb 23 cases (25.8\%), and trunk 14 cases (15.8\%). Tumor staging was made according to the Enneking staging system and the American Joint Committee on Cancer (AJCC) 7th edition staging system. Of the 89 patients, 41 were in stage IIA (46.1\%) and 48 in stage IIB (53.8\%) as per the Enneking staging

Table 1 Different types of chemotherapy drugs, dosage, and administration method and time

\begin{tabular}{llll}
\hline Chemotherapy drug & Dosage & Administration method & Administration time \\
\hline Ifosfamide & $2 \mathrm{~g} / \mathrm{m}^{2} /$ day & Intravenous drip & D1-D5 \\
Dacarbazine & $300 \mathrm{mg} / \mathrm{m}^{2} /$ day & Intravenous drip & D1-D5 \\
Adriamycin & $40 \mathrm{mg} / \mathrm{m}^{2}$ & Intravenous drip & D5 \\
\hline
\end{tabular}


system, but as per the AJCC staging system, 35 patients were in stage II (39.3\%) and 54 patients in stage III (60.7\%).

Furthermore, there were 75 patients receiving neoadjuvant chemotherapy (84.3\%), 9 patients receiving adjuvant chemotherapy (10.1\%), and 5 patients not receiving chemotherapy (5.6\%). Of the 84 patients receiving chemotherapy, 39 received less than six treatment courses and 45 received more than six treatment courses.

In the first treatment of the 89 patients, 81 (91\%) received extended resection in the tumor site and 8 received amputation rather than limb-sparing surgery due to neoplasm invading important nerves and blood vessels (Table 2).

\section{Treatment outcome}

The median follow-up time was 68.6 months (12 117 months), and that of the patients who survived was 76.3 months (52 117 months). Furthermore, at the last follow-up of the 89 patients, 72 survived and 17 died. Among the 17 patients who died, 16 died from tumor pulmonary metastasis and 1 died from other reasons. Until the last follow-up, 20 patients showed local recurrence, among whom 18 underwent extended resection in the tumor site and 2 amputation. In addition, 1 of the 20 patients who showed local recurrence died from pulmonary metastasis, and the others survived. Until the last followup, 17 patients showed distant metastasis, 16 of whom died from pulmonary metastasis and the remaining 1, who showed lymphatic metastasis, survived after extended resection (Table 2). The 5-year OS of the 89 patients was $80.2 \%$, and the 5 -year PFS was $60.5 \%$. The 5-year LC and 5-year FFDM were 78.8 and $80.8 \%$, respectively (Fig. 1 ).

\section{Influencing factor for prognosis}

Univariate analysis and multivariate analysis showed that the chemotherapy method and tumor size were the independent factors influencing the patients' OS $(P<0.05)$. Furthermore, the chemotherapy method was also the independent factor influencing FFDM ( $P$ $<0.05$ ) as shown in Table 3. The OS and FFDM of neoadjuvant chemotherapy were better than those of adjuvant chemotherapy $(P=0.028)$. The 5 -year OS was $84.5 \%$ for the patients receiving neoadjuvant chemotherapy and was $55.6 \%$ for the patients receiving adjuvant chemotherapy (Fig. 2). The tumor size could influence the patients' OS, and the OS was lower when the size was larger than $5 \mathrm{~cm}(P<0.05)$. The 5-year OS of the patients with a tumor size $\leq 5 \mathrm{~cm}$ was $91.4 \%$, and that of the patients with a tumor size $>5 \mathrm{~cm}$ was only $73.1 \%$ (Fig. 3). The 5 -year FFDM of the patients receiving neoadjuvant
Table 2 Baseline information of patients

\begin{tabular}{llll}
\hline Characteristic & Patients & $\begin{array}{l}\text { Neoadjuvant } \\
\text { chemotherapy }\end{array}$ & $\begin{array}{l}\text { Non-neoadjuvant } \\
\text { chemotherapy }\end{array}$ \\
\hline $\begin{array}{l}\text { Number } \\
\text { Gender }\end{array}$ & 89 & $75(84.3 \%)$ & $14(15.7 \%)$ \\
$\quad$ Male & 46 & $40(87 \%)$ & $6(13 \%)$ \\
$\quad$ Female & 43 & $35(81.4 \%)$ & $8(18.6 \%)$ \\
Age & & & \\
$\quad \begin{array}{l}<25 \text { years } \\
\text { old }\end{array}$ & 30 & $25(83.3 \%)$ & $5(16.7 \%)$ \\
$\quad \begin{array}{l}25 \text { years } \\
\text { old }\end{array}$ & 59 & $50(84.7 \%)$ & $9(15.3 \%)$ \\
$\begin{array}{l}\text { Tumor size } \\
\leq 5 \mathrm{~cm}\end{array}$ & & & \\
$>5 \mathrm{~cm}$ & 35 & $30(85.7 \%)$ & $5(14.3 \%)$ \\
& 54 & $45(83.3 \%)$ & $9(16.7 \%)$
\end{tabular}

Primary tumor

site

Limb

$20(87 \%)$

$3(13 \%)$

Lower limbs

$43(82.7 \%)$

$9(17.3 \%)$

Trunk

Shoulder-back

Hip

$12(85.7 \%)$

$2(14.3 \%)$

Chest wall

Pelvis

Neck

Pathological

pattern

$6(75.0 \%)$

$2(25.0 \%)$

$2(100 \%)$

$2(100 \%) \quad 0$

1 (100\%)

1 (100\%)

0

Bipolar type

Undifferentiated type

Unknown

$31(75.6 \%)$

10 (24.4\%)

$26(92.8 \%)$

$2(7.2 \%)$

8 (100\%)

$0(0 \%)$

Enneking staging

Phase IIA

$0(83.3 \%)$

$2(16.7 \%)$

Phase IIB

AJCC staging

Phase II

Phase III

$33(80.4 \%)$

$8(19.6 \%)$

48

$42(87.5 \%)$

$6(12.5 \%)$

Chemotherapy

course

$<6$

39

$\geq 6$

45

No

$30(85.7 \%)$

5 (14.3\%)

54

45 (83.3\%)

$9(16.7 \%)$

Surgical method

Amputation

$8(100 \%)$

$0(0 \%)$

Extended resection

81

$67(\%)$

$14(\%)$

Surgical margin

Positive 
Table 2 Baseline information of patients (Continued)

\begin{tabular}{llll}
\hline Negative & 86 & $72(83.7 \%)$ & $14(16.3 \%)$ \\
$\begin{array}{l}\text { The 1st visiting hospital } \\
\text { Our hospital }\end{array}$ & 20 & $17(85 \%)$ & $3(15 \%)$ \\
$\begin{array}{l}\text { Other hospital } \\
\text { Local recurrence }\end{array}$ & 69 & $58(84.1 \%)$ & $11(15.9 \%)$ \\
$\quad$ Yes & 20 & $17(85 \%)$ & $3(15 \%)$ \\
No & 69 & $58(84.1 \%)$ & $11(15.9 \%)$ \\
Distant metastasis & & & \\
Yes & 17 & $12(70.6 \%)$ & $5(29.4 \%)$ \\
No & 72 & $63(87.5 \%)$ & $9(12.5 \%)$ \\
Last follow-up state & & & \\
Died from disease & 16 & $11(68.7 \%)$ & $5(31.3 \%)$ \\
Died from other reasons & 1 & $0(0 \%)$ & $1(100 \%)$ \\
Survived & 72 & $64(88.8 \%)$ & $8(11.2 \%)$ \\
\hline
\end{tabular}

chemotherapy was $83.8 \%$, and that of the patients receiving non-neoadjuvant chemotherapy was $55.6 \%$ (Fig. 4). In this study, age $(<25$ or $\geq 25)$, chemotherapy treatment course $(<6$ or $\geq 6)$, and tumor site (extremities or trunk) had no significant influence on OS, PFS, LC, and FFDM.

\section{Discussion}

Surgery is the most common treatment for synovial sarcoma, resulting in a good prognosis. Till date, there is minimal information available on surgery-based combined treatment modalities and there is lack of data to prove their statistical significance over surgery. So to better elucidate whether clinicopathological characteristics and treatment are correlated with survival in patients with synovial sarcoma and to find specific prognostic factors, this study has been designed. The major results of this

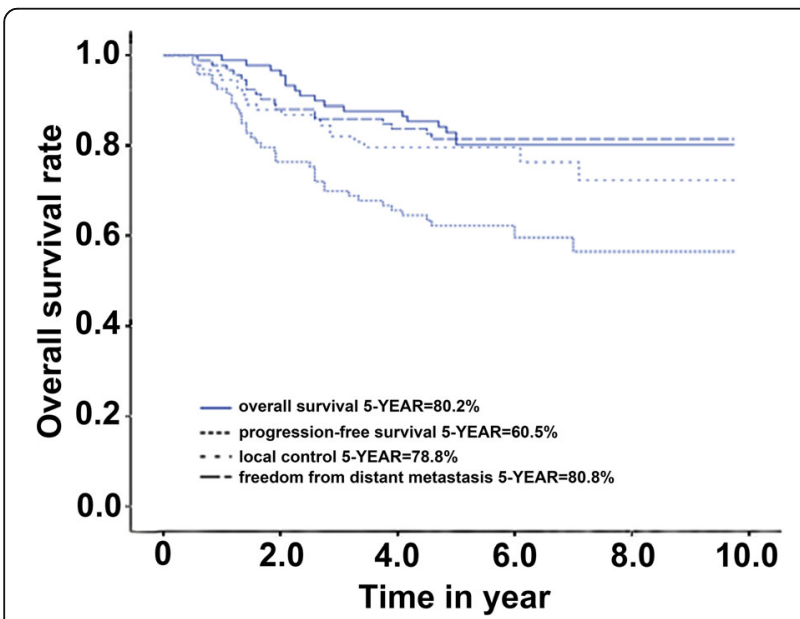

Fig. 1 Overall survival (OS), progression-free survival (PFS), local control, and freedom from distant metastasis (FFDM) study are that, in the 89 patients with synovial sarcoma, the 5 -year OS was $80.2 \%$ and neoadjuvant chemotherapy and tumor size were independent factors influencing the patients' survival time. Furthermore, neoadjuvant chemotherapy was also an independent factor influencing FFDM, suggesting that the application of neoadjuvant chemotherapy is of great clinical significance for improving synovial sarcoma patients' prognosis.

In reports during the 1990s, when synovial sarcoma was considered as a high-level malignant sarcoma, the 5 -year OS of patients with the disease was 40 76\% [8-11]. Recently, there were many reports on synovial sarcoma patients without metastasis in the primary diagnosis. Shi et al. [12] reported that in a follow-up study of 92 patients in a single-center study, the 5year OS was 61\%; Ferrari et al. reported 64.3\% (271 patients) [5]; Deshmukh et al. reported 70\% (108 patients) [13]; Guadagnolo et al. reported $76 \% \quad(150$ patients) [6]; Palmerini et al. reported 76\% (204 patients) [14]. Here, the 5-year OS of patients with synovial sarcoma was $80.2 \%$, similar to those of the recent studies but with slight improvement. The higher 5year OS of patients with synovial sarcoma might be related to the application of neoadjuvant chemotherapy to the patients enrolled in this study (84.3\%).

Local extended resection combined with radiotherapy has been widely applied in patients with synovial sarcoma overseas, reducing the local recurrence rate and increasing the $\mathrm{OS}[6,12,15]$. In addition, radiotherapy was not widely used in treating patients in early years, but a satisfactory result was also achieved by using local extended resection and neoadjuvant/adjuvant chemotherapy. In addition, synovial sarcoma was considered as a chemo-sensitive tumor [16-18]. Eilber et al. [19] reported that the 4-year OS of patients receiving chemotherapy and not receiving chemotherapy was 88 and 67\%, respectively, with a significant difference $(P<0.05)$ in a 101 -case report. In our study, the 5-year OS of patients receiving and not receiving chemotherapy was 81.4 and $60 \%$, respectively, which is in line with the above report.

Multicenter studies demonstrated that chemotherapy mainly on ifosfamide could improve the survival time of patients in the treatment of high-level soft tissue sarcoma [20-22], and Eilber et al. also found the same therapeutic effect in patients with synovial sarcoma. We used the MAID regimen to treat 84 patients by chemotherapy. In a previous study, Mullen et al. [23] reported that the application of neoadjuvant chemotherapy combined with radiotherapy greatly improved the OS, LC, and FFDM compared with the control group (without chemotherapy or with other chemotherapy) in treating high-level soft tissue sarcoma $(P<0.05)$. Neoadjuvant chemotherapy has been reported in the treatment of 
Table 3 Results of single-factor analysis

\begin{tabular}{|c|c|c|c|c|c|c|c|c|c|}
\hline Influencing factor & Number & 5-year OS (\%) & $P$ & 5-year PFS (\%) & $P$ & 5-year LC (\%) & $P$ & 5-year FFDM (\%) & $P$ \\
\hline Totality & 89 & 80.2 & & 60.5 & & 78.8 & & 80.8 & \\
\hline Age & & & 0.302 & & 0.501 & & 0.979 & & 0.685 \\
\hline$<25$ years old & 30 & 86.1 & & 66.5 & & 79.7 & & 83.2 & \\
\hline$\geq 25$ years old & 59 & 77.1 & & 57.5 & & 78.4 & & 79.5 & \\
\hline Tumor size & & & 0.048 & & 0.606 & & 59.2 & & 0.053 \\
\hline$\leq 5 \mathrm{~cm}$ & 35 & 91.4 & & 65.7 & & 76.8 & & 91.4 & \\
\hline$>5 \mathrm{~cm}$ & 54 & 73.1 & & 57.2 & & 80.0 & & 73.9 & \\
\hline Chemotherapy method & & & 0.015 & & 0.313 & & 0.883 & & 0.028 \\
\hline Adjuvant chemotherapy & 9 & 55.6 & & 44.4 & & 71.1 & & 55.6 & \\
\hline Neoadjuvant chemotherapy & 75 & 84.5 & & 63.8 & & 79.3 & & 83.8 & \\
\hline Chemotherapy course & & & 0.287 & & 0.726 & & 0.958 & & 0.403 \\
\hline$<6$ & 39 & 76.8 & & 59.0 & & 78.7 & & 76.9 & \\
\hline$\geq 6$ & 45 & 85.2 & & 64.0 & & 79.0 & & 84.1 & \\
\hline
\end{tabular}

synovial sarcoma previously, but not as the main treatment. In this study, 72 patients received neoadjuvant chemotherapy and 9 received adjuvant chemotherapy; the 5-year OS was 84.5 and $55.6 \%(P<0.05)$ and FFDM was 83.8 and $55.6 \%$, respectively $(P<0.05)$. We believed that neoadjuvant chemotherapy could bring more benefits for patients with synovial sarcoma compared with adjuvant chemotherapy because it could provide more direct observation of the sensitivity of tumor to chemotherapy drugs before operation and more evidence for postoperative chemotherapy and options of chemotherapy regimens which in turn increase patients' survival time and control distant metastasis. Mullen et al. used neoadjuvant chemotherapy to perform chemotherapy with six treatment courses [23]. Among the 84 patients in our study, there was no significant difference between the patients receiving more than six courses and those receiving less than six courses in the OS (76.8 vs $85.2 \%)$, PFS (59.0 vs $64.0 \%)$, LC (78.7 vs $79.0 \%$ ), and FFDM (76.9

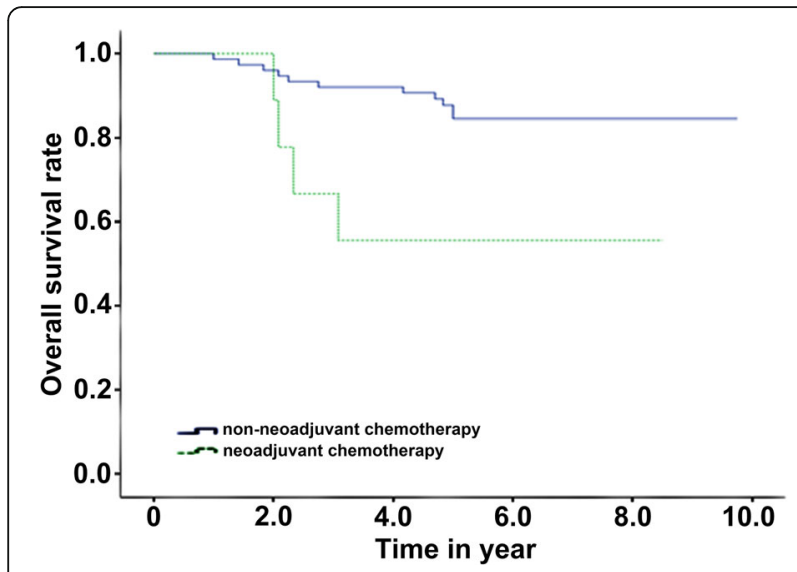

Fig. 2 Total overall survival (OS) for different chemotherapy methods vs $84.1 \%)(P>0.05)$. How many disease courses are appropriate for chemotherapy in patients with synovial sarcoma still needs further study.

Local recurrence of tumor is related to the tumor moderate or poor differentiation area, tumor size [24], and resection margin [6, 25-27]. The 5-year LC in our study was $78.8 \%$, and tumor size $(\leq 5$ or $>5 \mathrm{~cm})$ and resection margin (positive or negative) had no significant difference in LC. Tumor size is an important factor influencing prognosis in soft connective tissue tumor $[19,27]$, which is also very important in synovial sarcoma $[5,12,13,25,28]$. A larger tumor size is a reason for poor prognosis, which was proved in our study. A tumor size $>5 \mathrm{~cm}$ indicated poor survival time and lower FFDM. Whether age could influence the prognosis of patients with synovial sarcoma is inconclusive, and it was reported that the age grouping on the differential OS was different $[5,12,16,24,29]$. In our study, age had no significant difference in prognosis. It is still

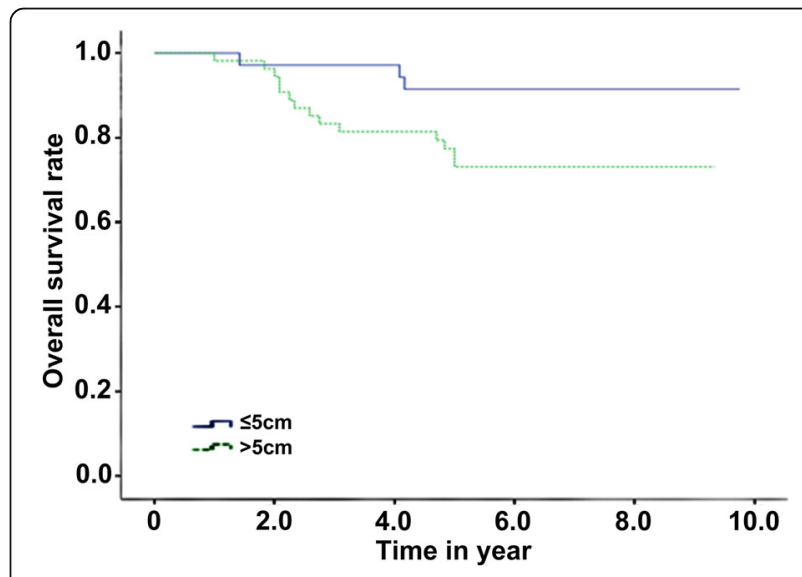

Fig. 3 Total overall survival (OS) for different tumor sizes 


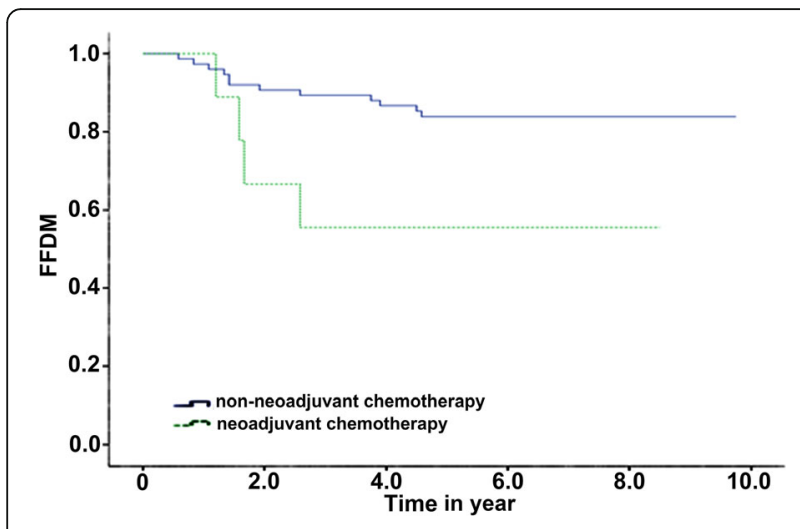

Fig. 4 Freedom from distant metastasis (FFDM) for different chemotherapy methods

controversial whether unipolar type or bipolar type had influence on survival time [3,11,30-33], but we found that they had no significant difference in survival time.

However, there were still some limitations in this study. First, this was a retrospective study and the conclusion needs further prospective study. Secondly, the case number using neoadjuvant chemotherapy was more, but that using non-adjuvant chemotherapy was less. Therefore, a larger sample would be conducive to further verification. Because this was a single-center study with consistency in treatment and management of the patients, the conclusion is of great clinical significance for understanding the prognosis of this rare disease.

\section{Conclusions}

Through a retrospective study of 89 patients with synovial sarcoma, it was proved that neoadjuvant chemotherapy and tumor size were the independent factors influencing patients' survival time and neoadjuvant chemotherapy was also an independent relevant factor influencing distant metastasis. Above all, it was proved that neoadjuvant chemotherapy was conducive to patients with synovial sarcoma and could improve the survival time and control distant metastasis. This study is of great clinical significance for improving synovial sarcoma patients' prognosis.

\section{Abbreviations}

FFDM: Freedom from distant metastasis; LC: Local control; OS: Overall survival; PFS: Progression-free survival

\section{Acknowledgements}

None.

\section{Funding}

This study was supported by the National Natural Science Foundation of China (No. 81472513).

Availability of data and materials Not applicable.

\section{Authors' contributions}

YW, WB, GH, JPJ, and MX conceived and designed the study. YW acquired the data. YW and WB analyzed and interpreted the data. YW drafted the manuscript. YW, WB, GH, JPJ, and MX critically revised the manuscript. YW, $W B, G H, J P J$, and $M X$ gave final approval of the manuscript. YW and WB are the guarantors of the integrity of the entire study. YW performed the statistical analysis. YW, WB, GH, JPJ, and MX defined the intellectual content. YW performed the literature research. YW, WB, GH, JPJ, and MX performed the clinical studies. WB, GH, JPJ, and MX provided administrative, technical, or material support. WB, GH, JPJ, and MX supervised the study. All authors read and approved the final manuscript.

\section{Competing interests}

The authors declare that they have no competing interests.

\section{Consent for publication}

Not applicable.

\section{Ethics approval and consent to participate}

The relevant medical records were identified by the Ethics Committee of PLA General Hospital, and all the patients had signed the informed consent form.

\section{Publisher's Note}

Springer Nature remains neutral with regard to jurisdictional claims in published maps and institutional affiliations.

Received: 24 January 2017 Accepted: 23 April 2017

Published online: 11 May 2017

\section{References}

1. Enzinger FM, Weiss SW. Soft tissue tumours. Chicago: Mosby, Inc; 2001.

2. Thway K, Fisher C. Synovial sarcoma: defining features and diagnostic evolution. Ann Diagn Pathol. 2014;18(6):369-80. doi:10.1016/j.anndiagpath. 2014.09.002.

3. Kawai A, Woodruff J, Healey JH, Brennan MF, Antonescu CR, Ladanyi M. SYTSSX gene fusion as a determinant of morphology and prognosis in synovial sarcoma. N Engl J Med. 1998;338(3):153-60. doi:10.1056/ nejm199801153380303.

4. Spillane AJ, A'Hern R, Judson IR, Fisher C, Thomas JM. Synovial sarcoma: a clinicopathologic, staging, and prognostic assessment. J Clin Oncol. 2000;18(22):3794-803.

5. Ferrari A, Gronchi A, Casanova M, Meazza C, Gandola L, Collini P, et al. Synovial sarcoma: a retrospective analysis of 271 patients of all ages treated at a single institution. Cancer. 2004;101(3):627-34. doi:10.1002/cncr.20386.

6. Guadagnolo BA, Zagars GK, Ballo MT, Patel SR, Lewis VO, Pisters PW, et al. Long-term outcomes for synovial sarcoma treated with conservation surgery and radiotherapy. Int J Radiat Oncol Biol Phys. 2007;69(4):1173-80. doi:10.1016/j.jijobp.2007.04.056.

7. Weingrad DN, Rosenberg SA. Early lymphatic spread of osteogenic and softtissue sarcomas. Surgery. 1978;84(2):231-40.

8. Fletcher JA, Kozakewich HP, Hoffer FA, Lage JM, Weidner N, Tepper R, et al. Diagnostic relevance of clonal cytogenetic aberrations in malignant softtissue tumors. N Engl J Med. 1991;324(7):436-42. doi:10.1056/ nejm199102143240702.

9. Mullen JR, Zagars GK. Synovial sarcoma outcome following conservation surgery and radiotherapy. Radiother Oncol. 1994;33(1):23-30.

10. Shmookler BM, Enzinger FM, Brannon RB. Orofacial synovial sarcoma: a clinicopathologic study of 11 new cases and review of the literature. Cancer. 1982;50(2):269-76.

11. Singer S, Baldini EH, Demetri GD, Fletcher JA, Corson JM. Synovial sarcoma: prognostic significance of tumor size, margin of resection, and mitotic activity for survival. J Clin Oncol. 1996;14(4):1201-8.

12. Shi W, Indelicato DJ, Morris CG, Scarborough MT, Gibbs CP, Zlotecki RA. Long-term treatment outcomes for patients with synovial sarcoma: a 40year experience at the University of Florida. Am J Clin Oncol. 2013;36(1):838. doi:10.1097/COC.0b013e31823fe450.

13. Deshmukh R, Mankin HJ, Singer S. Synovial sarcoma: the importance of size and location for survival. Clin Orthop Relat Res. 2004;419:155-61. 
14. Palmerini E, Staals EL, Alberghini M, Zanella L, Ferrari C, Benassi MS, et al. Synovial sarcoma: retrospective analysis of 250 patients treated at a single institution. Cancer. 2009;115(13):2988-98. doi:10.1002/cncr.24370.

15. Song S, Park J, Kim HJ, Kim IH, Han I, Kim HS, et al. Effects of adjuvant radiotherapy in patients with synovial sarcoma. Am J Clin Oncol. 2014 doi:10.1097/coc.0000000000000148.

16. Spurrell EL, Fisher C, Thomas JM, Judson IR. Prognostic factors in advanced synovial sarcoma: an analysis of 104 patients treated at the Royal Marsden Hospital. Ann Oncol. 2005;16(3):437-44. doi:10.1093/annonc/mdi082.

17. Kampe CE, Rosen G, Eilber F, Eckardt J, Lowenbraun S, Foster J, et al. Synovial sarcoma. A study of intensive chemotherapy in 14 patients with localized disease. Cancer. 1993;72(7):2161-9.

18. Rosen G, Forscher C, Lowenbraun S, Eilber F, Eckardt J, Holmes C, et al. Synovial sarcoma. Uniform response of metastases to high dose ifosfamide. Cancer. 1994:73(10):2506-11.

19. Eilber FC, Brennan MF, Eilber FR, Eckardt JJ, Grobmyer SR, Riedel E, et al. Chemotherapy is associated with improved survival in adult patients with primary extremity synovial sarcoma. Ann Surg. 2007;246(1):105-13. doi:10.1097/01.sla.0000262787.88639.2b.

20. Eilber FC, Rosen G, Eckardt J, Forscher C, Nelson SD, Selch M, et al. Treatment-induced pathologic necrosis: a predictor of local recurrence and survival in patients receiving neoadjuvant therapy for high-grade extremity soft tissue sarcomas. J Clin Oncol. 2001;19(13):3203-9.

21. DeLaney TF, Spiro IJ, Suit HD, Gebhardt MC, Hornicek FJ, Mankin HJ, et al. Neoadjuvant chemotherapy and radiotherapy for large extremity soft-tissue sarcomas. Int J Radiat Oncol Biol Phys. 2003:56(4):1117-27.

22. Grobmyer SR, Maki RG, Demetri GD, Mazumdar M, Riedel E, Brennan MF, et al. Neo-adjuvant chemotherapy for primary high-grade extremity soft tissue sarcoma. Ann Oncol. 2004;15(11):1667-72. doi:10.1093/annonc/mdh431.

23. Mullen JT, Kobayashi W, Wang JJ, Harmon DC, Choy E, Hornicek FJ, et al. Long-term follow-up of patients treated with neoadjuvant chemotherapy and radiotherapy for large, extremity soft tissue sarcomas. Cancer. 2012; 118(15):3758-65. doi:10.1002/cncr.26696.

24. de Silva MV, McMahon AD, Reid R. Prognostic factors associated with local recurrence, metastases, and tumor-related death in patients with synovial sarcoma. Am J Clin Oncol. 2004;27(2):113-21.

25. Trassard M, Le Doussal V, Hacene K, Terrier P, Ranchere D, Guillou L, et al. Prognostic factors in localized primary synovial sarcoma: a multicenter study of 128 adult patients. J Clin Oncol. 2001;19(2):525-34.

26. Singer S, Corson JM, Gonin R, Labow B, Eberlein TJ. Prognostic factors predictive of survival and local recurrence for extremity soft tissue sarcoma. Ann Surg. 1994;219(2):165-73,

27. Brecht IB, Ferrari A, Int-Veen C, Schuck A, Mattke AC, Casanova M, et al. Grossly-resected synovial sarcoma treated by the German and Italian Pediatric Soft Tissue Sarcoma Cooperative Groups: discussion on the role of adjuvant therapies. Pediatr Blood Cancer. 2006:46(1):11-7. doi:10.1002/pbc.20502.

28. Lewis JJ, Antonescu CR, Leung DH, Blumberg D, Healey JH, Woodruff JM, et al. Synovial sarcoma: a multivariate analysis of prognostic factors in 112 patients with primary localized tumors of the extremity. J Clin Oncol. 2000;18(10):2087-94.

29. Okcu MF, Munsell M, Treuner J, Mattke A, Pappo A, Cain A, et al. Synovial sarcoma of childhood and adolescence: a multicenter, multivariate analysis of outcome. J Clin Oncol. 2003;21 (8):1602-11. doi:10.1200/jco.2003.07.008.

30. Wisanuyotin T, Radapat K, Sirichativapee W, Paholpak P, Kosuwon W, Sumnanoont $C$, et al. Prognostic factors and clinical outcomes in synovial sarcoma of the extremities. Asia Pac J Clin Oncol. 2013;9(1):80-5. doi:10. 1111/j.1743-7563.2012.01563.x.

31. Paulino AC. Synovial sarcoma prognostic factors and patterns of failure. Am J Clin Oncol. 2004;27(2):122-7.

32. Koh KH, Cho EY, Kim DW, Seo SW. Multivariate analysis of prognostic factors in synovial sarcoma. Orthopedics. 2009;32(11):824. doi:10.3928/0147744720090922-12

33. Inagaki H, Nagasaka T, Otsuka T, Sugiura E, Nakashima N, Eimoto T. Association of SYT-SSX fusion types with proliferative activity and prognosis in synovial sarcoma. Mod Pathol. 2000;13(5):482-8. doi:10.1038/modpathol.3880083.

\section{Submit your next manuscript to BioMed Central and we will help you at every step:}

- We accept pre-submission inquiries

- Our selector tool helps you to find the most relevant journal

- We provide round the clock customer support

- Convenient online submission

- Thorough peer review

- Inclusion in PubMed and all major indexing services

- Maximum visibility for your research

Submit your manuscript at www.biomedcentral.com/submit
Biomed Central 